\title{
As relações de gênero no contexto socioeconômico e cultural brasileiro: estudo com mulheres motoristas de aplicativos de mobilidade urbana
}

\author{
Ana Paula de Oliveira Amaral Colodetti ${ }^{1}$ \\ Marlene Catarina de Oliveira lopes Melo ${ }^{1}$ \\ ${ }^{1}$ Centro Universitário Unihorizontes, Belo Horizonte - MG, BrasiL
}

\section{Resumo}

Este estudo teve por objetivo analisar como as relações de gênero e o contexto socioeconômico e cultural brasileiro são percebidos por mulheres motoristas de aplicativos de mobilidade urbana em sua atuação profissional e no ambiente de trabalho. A metodologia adotada para o desenvolvimento desta pesquisa foi uma abordagem qualitativa-descritiva e interpretativa, tendo sido entrevistadas 11 mulheres atuantes como motoristas de aplicativos de transporte na região metropolitana de Belo Horizonte, Minas Gerais. Os dados obtidos a partir das entrevistas com roteiro semiestruturado foram analisados considerando a concepção de gênero de Scott (1995), os pressupostos teóricos de dominação masculina e de violência simbólica de Bourdieu (2002) e a percepção da mulher como sujeito de transformação do campo social e cultural de Touraine (2007). Ao final do estudo, constatou-se um movimento incipiente de aceitação social e cultural percebido pelas entrevistadas em sua atuação como motoristas, impulsionado principalmente por um cenário de crise econômica e de desemprego, mas também como consequência do empoderamento da mulher que, não se reconhecendo vítima de uma estrutura patriarcal opressora, persistente e dominante, se percebe sujeito transformador de sua própria realidade.

Palavras-chave: Gênero. Trabalho. Mulheres motoristas.

Gender relations in the Brazilian socioeconomic and cultural context: a study with female drivers of urban mobilityapps

\begin{abstract}
This study analyzed how gender relations and the Brazilian socioeconomic and cultural context are perceived by female drivers of urban mobility apps in their professional performance and work environment. Using a qualitative-descriptive and interpretative approach, interviews were conducted with 11 women working as drivers of transport apps in the metropolitan region of Belo Horizonte, Minas Gerais. The data obtained from the semi-structured interviews were analyzed considering Scott's gender conception (1995), the theoretical assumptions of male domination and symbolic violence by Bourdieu (2002), and the perception of women as subjects of transformation in the social and cultural field by Touraine (2007). The results showed an incipient movement of social and cultural acceptance perceived by the interviewees in their performance as drivers, mainly caused by a scenario of economic crisis and unemployment, but also as a consequence of female empowerment in a system where they do not recognize themselves as victims of an oppressive, persistent, and dominant patriarchal structure, but as transforming subjects of their own reality.
\end{abstract}

Keywords: Gender. Work. Female drivers.

Relaciones de género en el contexto socioeconómico y cultural brasileño: un estudio con mujeres conductoras de aplicaciones de movilidad urbana

\section{Resumen}

Este estudio tuvo por objeto analizar cómo las mujeres conductoras de aplicaciones de movilidad urbana perciben las relaciones de género y el contexto socioeconómico y cultural brasileño en su actuación profesional y ambiente laboral. La metodología que se adoptó para el desarrollo de esta investigación fue un enfoque cualitativo, descriptivo e interpretativo. Se entrevistó a 11 mujeres que actúan como conductoras de aplicaciones de transporte en la zona metropolitana de Belo Horizonte, Minas Gerais. Los datos obtenidos en las entrevistas con guion semiestructurado se analizaron bajo la concepción de género de Scott (1995), de las premisas teóricas de dominación masculina y de violencia simbólica de Bourdieu (2002) y de la percepción de la mujer como sujeto de transformación del campo social y cultural de Touraine (2007). Al término del estudio, se pudo constatar un incipiente movimiento de aceptación social y cultural percibido por las entrevistadas en su actuación como conductoras, potenciado principalmente por un escenario de crisis económica y de desempleo, y también como consecuencia del empoderamiento de la mujer que, al no reconocerse como víctima de una estructura patriarcal opresora, persistente y dominante, se percibe como sujeto transformador de su propia realidad.

Palabras clave: Género. Trabajo. Mujeres conductoras. 


\section{INTRODUÇÃO}

Os estudos sobre as relações de gênero e suas desigualdades não podem ser compreendidos se desconsiderados os aspectos históricos, culturais, sociais, econômicos e políticos. É necessária uma visão ampla que englobe não apenas o sistema de parentesco, mas também o mercado de trabalho, a educação, o sistema político e as relações de poder que envolvem homens e mulheres (Louro, 2008; Scott, 1995; Silva, 2016).

O gênero, percebido como categoria analítica constitutiva das relações de poder e das construções sociais e culturais fundamentadas em diferenças biológicas, permite uma melhor compreensão das estruturas normativas hierarquizadas (Bogéa, 2017; Siqueira, 2016). A análise do gênero também remete à estruturação do mundo do trabalho, sustentando a construção de instituições sociais, nas quais o papel desempenhado por homens e mulheres é delimitado. Nessa perspectiva, a divisão de tarefas é entendida como um construto social, refletindo mais uma definição cultural do que as próprias necessidades biológicas. A influência da sociedade, cultura, religião, família, política e etnicidade é igualmente percebida nos comportamentos femininos e masculinos na esfera laboral (Pinto, Nunes \& Fazenda, 2014).

Nesse sentido, as desigualdades e dificuldades sofridas pelas mulheres no mercado de trabalho e a submissão a uma dupla jornada (trabalho doméstico e trabalho remunerado) resultam em maior suscetibilidade na ocupação de atividades informais e precárias, e no exercício de profissões consideradas femininas conforme estereótipos culturalmente estabelecidos (Abramo, 2016). Com isso, a escolha da mulher por profissões ainda marcadas por características tipicamente masculinas, como a de motorista (Beigi, Nayyeri \& Shirmohammadi, 2020; Scheller, 2009), tem permitido discussões e questionamentos sobre as configurações da organização do trabalho (Fontana \& Costa, 2016).

A profissão de motorista no Brasil, anteriormente associada aos condutores de táxi, ônibus, caminhões, entre outros, foi completamente reformulada após a chegada dos aplicativos de mobilidade urbana. A ideia desse modelo de negócio surgiu no ano de 2009, em São Francisco, nos Estados Unidos, com a criação da empresa Uber.

Implementada no Brasil somente em maio de 2014, a proposta negocial consiste na disponibilização, por meio de uma plataforma on-line, de um serviço privado de transporte de fácil acesso e preços reduzidos, possibilitando a qualquer pessoa que se cadastre o exercício da profissão de motorista. Diferenciado pela facilidade de adesão, flexibilidade de horários e possibilidade de ganhos financeiros, esse modelo de trabalho tornou-se atrativo para homens e mulheres não inseridos no mercado de trabalho tradicional (Codagnone, Abadie \& Biagi, 2016; Franco \& Ferraz, 2019; Zanatta, De Paula \& Kira, 2017), diretamente afetados pela crise econômica brasileira ou em busca de complementação da renda (Peticca-Harris, Degama \& Ravishankar, 2018; Valente, Patrus \& Guimarães, 2019). A sua rápida aceitação e expansão resultou na criação de outras empresas (99POP, Cabify, Venuxx, Cruzeiro Go, Mobbi, Uai Move) e em profundas mudanças econômicas e sociais.

Assim, ao reestruturar o conceito de deslocamento, o advento dos aplicativos de transporte também promoveu o crescimento da profissão e uma redefinição da figura do motorista, fortemente associada ao sexo masculino (Beigi et al., 2020; Nogueira \& Castelhano, 2012; Scheller, 2009), mas em processo de feminização e ajustamento nos papéis de gênero (Fallavena, 2017). Apesar disso, esse ambiente de trabalho brasileiro continua dominado pela figura masculina, já que apenas $6 \%$ dos 600 mil motoristas cadastrados são mulheres (Uber, 2020). Um dos fatores que contribui para esse cenário é a cultura, que não apenas reproduz como legitima estruturas sociais hierarquizadas e desiguais, criando estereótipos e imposições estigmatizantes à mulher na segmentação de tarefas, na atribuição e no exercício de cargos e funções. No caso da cultura brasileira, o modelo aristocrático da família patriarcal, estabelecido no período colonial, ainda persiste nas relações políticas e sociais contemporâneas, contribuindo para a dominação masculina e reforçando as desigualdades de gênero (Fenili, 2016; Pinto et al., 2014).

Segundo Bourdieu (2002), a dominação masculina e a violência simbólica se legitimam por meio do "habitus", cuja definição remete aos comportamentos e ações do indivíduo, conscientes ou inconscientes, formados por experiências vivenciadas em determinado contexto histórico, econômico, social e familiar. Nesse sentido, a mulher é retratada como vítima de estruturas sociais objetivamente construídas para oprimi-la, mas também como reprodutora de condutas que acabam sendo naturalizadas. Por outro lado, Touraine (2007) entende que a situação das mulheres não se limita à dominação que sofrem, pois não se percebem somente vítimas, mas também sujeitos de transformação cultural e social, agentes de sua história e responsáveis por seu empoderamento e emancipação. 
Considerando a concepção de gênero de Scott (1995), os pressupostos teóricos de dominação masculina e de violência simbólica de Bourdieu (2002) e a ideia de reforço da identidade da mulher como sujeito de transformação do campo social e cultural desenvolvida por Touraine (2007), o presente estudo teve por objetivo analisar como as relações de gênero e o contexto socioeconômico e cultural brasileiro são percebidos por mulheres motoristas de aplicativos de mobilidade urbana em sua atuação profissional e no ambiente de trabalho. Foi, assim, realizada uma pesquisa do tipo descritiva e de abordagem qualitativa e interpretativa, mediante a condução de 11 entrevistas com mulheres motoristas de aplicativos de transporte na região metropolitana de Belo Horizonte, Minas Gerais.

As relações de gênero e as desigualdades em ambientes de trabalho predominantemente masculinos têm sido objeto de estudo, a fim de se compreender como a subordinação feminina existente em diversas esferas repercute no âmbito laboral e como o contexto histórico é capaz de promover não apenas assimetrias e dominação, mas também emancipação e empoderamento (Amorim, 2015). As transformações sociais, políticas, econômicas e culturais assumem importante papel na reestruturação da dominação masculina (Silva, 2011), ao mesmo tempo em que as conquistas feministas, tais como a educação e a alfabetização de mulheres (Gomes, 2019; Mészáros, 2008; Tozetti et al., 2016) representam maior autonomia feminina, participação no mercado de trabalho, independência financeira e rearticulação das relações de poder (Melo, 2012, 2018).

Este estudo mostra-se relevante para um aprofundamento e desenvolvimento das questões que envolvam esse tema, particularmente aquelas que busquem estabelecer conexões entre a desigualdade de gênero e o contexto socioeconômico, cultural, histórico e político.

\section{REFERENCIAL TEÓRICO}

\section{Relações de gênero}

O termo gênero surge na década de 1970, juntamente com o movimento feminista contemporâneo para designar a construção social das relações entre os sexos, em oposição ao critério biológico utilizado para justificar as diferenças e desigualdades entre homens e mulheres. $O$ destaque ao aspecto social, cultural e relacional como forma de dissociação do determinismo biológico pretendia mudar paradigmas e estruturas sociais consolidadas (Bogéa, 2017; Bourdieu, 2002; Prado, Di Giorgi \& Ribeiro, 2015; Scott, 1995; Silva, 2016).

O termo passou a apresentar diversas definições, amparando-se principalmente em teorias de caráter restrito e generalizador ou limitando-se a descrever as relações entre os sexos (Scott, 1995). Ora empregado como substituto de mulheres, ora conceituado como o estudo de mulheres e homens em conjunto, o termo gênero também passou a designar as relações sociais entre os sexos, as construções culturais das funções adequadas a homens e mulheres, e até mesmo a diferenciar a prática sexual dos papéis sociais masculinos e femininos (Biroli, 2012; Gomes, 2019).

Segundo Scott (1995), as teorias do patriarcado, das relações econômicas de produção e do gênero como categoria a-histórica, quando empregadas isoladamente, seriam insuficientes para explicar as desigualdades entre homens e mulheres, fazendo-se necessária uma abordagem do gênero como categoria analítica inserida em um contexto político e acadêmico. Assim, as relações de gênero também devem considerar as circunstâncias organizacionais (relações de parentesco), institucionais (educação), políticas (sufrágio) e mercadológicas (Pinto et al., 2014; Scott, 1995), permitindo a contextualização temporal e espacial, e a formação de uma identidade feminina aliada a uma investigação histórica (Louro, 2004; Scott, 1995).

Do mesmo modo, as desigualdades de gênero oriundas de estruturas normativas e objetivas hierarquizadas e apoiadas em teorias biológicas devem ser analisadas a partir de uma construção histórico e política apta a esclarecer as relações de poder que produzem essas diferenciações e exclusões sociais (Bogéa, 2017; Scott, 2005).

Como forma de compreender as relações de gênero e o contexto socioeconômico e cultural brasileiro no ambiente de trabalho das mulheres motoristas de aplicativos de transporte, adota-se nesse estudo o entendimento de gênero como categoria analítica de construção histórica e cultural das relações sociais e de poder (Antunes, 2010; Louro, 2004; Scott, 1995), legitimadas pela estrutura de dominação masculina naturalizada pela socialização do biológico (Bourdieu, 2002), paradoxalmente à concepção da mulher como sujeito de transformação social e agente de sua própria vida (Touraine, 2007).

Diante disso, destaca-se que o estudo de gênero somente será possível caso haja uma redefinição e reestruturação em um contexto de igualdade política e social que compreenda sexo, classe e raça (Scott, 1995). 


\section{As relações de gênero na perspectiva da dominação masculina de Bourdieu}

As relações de gênero na perspectiva de Bourdieu (2002) encontram-se enraizadas em uma estrutura social de dominação masculina, naturalizada e justificada pelo determinismo biológico e pela eficácia de mecanismos oriundos dessa estrutura e que contribuem para a reprodução e permanência das diferenças substanciais entre homens e mulheres. Assim, essa arbitrária dominação, cujas raízes têm origem na distinção biológica entre os sexos, se estende para todas as esferas sociais, inclusive para a divisão do trabalho (Alves \& Castro, 2018). A família patriarcal, como um dos fatores institucionais responsáveis pelas desigualdades de gênero, legitima essa divisão, tornando-a natural (Mendes, 2005).

Bourdieu (2002), ao examinar detidamente a dominação masculina e a violência simbólica, produzidas e reproduzidas por meio do habitus - incorporação de percepções e comportamentos desenvolvidos no âmbito familiar, religioso, escolar e institucional concebe a mulher como vítima de uma estrutura social opressora, mas para a qual também contribui. Ao mesmo tempo, reconhece o surgimento de mudanças, considerando o aumento do acesso das mulheres à instrução um dos fatores decisivos na modificação da divisão do trabalho, na independência econômica da mulher e na reorganização das relações familiares.

Dessa forma, ainda que o acesso à educação e o ingresso no mercado de trabalho impacte a vida das mulheres, permanecerão as mesmas vítimas de uma estrutura de dominação masculina, na qual os homens continuam detentores do poder político e econômico. A ruptura dessa estrutura de dominação simbólica existente entre homens e mulheres somente seria possível por meio de "uma transformação radical das condições sociais de produção das tendências que levam os dominados a adotar, sobre os dominantes e sobre si mesmos, o próprio ponto de vista dos dominantes" (Bourdieu, 2002, p. 54).

\section{As relações de gênero na percepção de Alain Touraine}

O gênero, na concepção de Touraine (2007), é admitido como categoria analítica e relacional (Antunes, 2010; Louro, 2004; Scott, 1995) e como mecanismo de transformação das estruturas sociais (Prado et al., 2015). Contudo, apesar de o autor não priorizar as particularidades das questões culturais e históricas e os modelos estruturais patriarcais estabelecidos, reconhece as profundas mudanças conquistadas pelos movimentos sociais feministas, que permitiram às mulheres assumir a atual condição de sujeitos.

Partindo dessa premissa, verifica-se uma distinção na percepção da mulher retratada por Touraine (2007) e a mulher descrita por Bourdieu (2002). Enquanto a mulher, na visão de Bourdieu (2002) é vítima, incapaz de romper as configurações sociais estabelecidas, a mulher sob a ótica de Touraine (2007) revela-se sujeito de transformação social, capaz de se emancipar das desigualdades de gênero socialmente determinadas e de se empoderar enquanto autora social.

Ainda que centralize o papel das mulheres na luta contra a desigualdade de gênero, Touraine (2007), assim como Bourdieu (2002), atesta a contribuição feminina no fortalecimento e na reprodução das estruturas sociais que as oprimem. 0 autor reconhece a existência de um sistema de dominação masculina persistente, embora não absoluto, mas alerta que, apesar da lógica de dominação, o novo espaço que as mulheres buscam construir "define-se por um ultrapassar das relações de poder e por uma referência constante a si próprias" (Touraine, 2007, p. 118).

Nesse sentido, destaca-se a importância do contexto socioeconômico e cultural na atuação das mulheres, sendo a transformação cultural o elemento de maior significação de seus atos. Isso porque as mulheres, ao definirem a si próprias em nível de cultura, consolidam-se como sujeitos principais de um novo modelo em desenvolvimento, caracterizado por certa harmonização e busca de igualdade entre homens e mulheres, em oposição a um sistema hierárquico e de superioridade masculina (Touraine, 2007, p. 117).

\section{O contexto socioeconômico e cultural}

Segundo Bourdieu (2002), a cultura e a economia são os critérios mais importantes para a construção de um espaço social das sociedades desenvolvidas. A cultura é responsável pela formação de estruturas sociais e comportamentos que as legitimam, sendo reforçada pelas instituições escola e família, que reproduzem as estruturas normativas e hierárquicas existentes.

Como parte constitutiva das relações sociais que legitimam o gênero, a cultura contribui significativamente para a formação de comportamentos, atitudes e estereótipos responsáveis pelas diferenças e desigualdades estabelecidas, e para justificar a inferioridade ou submissão de um sujeito em relação a outro (Scott, 1995). Com isso, discursos excludentes e misóginos são socialmente normatizados a partir de uma significação cultural embasada unicamente em aspectos biológicos (Silva, 2016). 
Nessa acepção, a educação revela-se importante elemento da cultura, capaz de promover a emancipação de mulheres submetidas a uma sociedade patriarcal, garantir maior autonomia e reduzir as desigualdades de gênero. Torna-se, assim, instrumento apto a viabilizar transformações sociais e a ruptura de estruturas dominantes (Gomes, 2019; Melo, 2018; Telles, 2013; Tozetti et al., 2016).

As características culturais e o contexto histórico de cada sociedade devem ser levados em consideração no estudo das relações de gênero (Fontana \& Costa, 2016; Scott, 1995). No que tange ao contexto socioeconômico e cultural brasileiro, suas particularidades foram determinantes para a organização social do país, estruturado com base em um modelo aristocrático da família patriarcal e em um sistema escravocrata. Consequentemente, o tratamento distinto conferido a homens e mulheres por esse sistema desigual e machista repercute nas relações de poder e nas esferas política, laboral, econômica e social (Fenili, 2016; Pinto et al., 2014).

Não obstante a crescente participação de mulheres no mercado de trabalho e no sustento econômico da família, discriminações e desigualdades ainda persistem, notadamente em função do gênero (Ávila \& Ferreira, 2014). Assim, De Souza, Baldwin e Rosa (2000) enfatizam que, apesar do progresso nas questões envolvendo o trabalho das mulheres, há também uma estagnação decorrente da definição dos papéis de gênero reproduzidos segundo a cultura de uma sociedade machista brasileira. Nesse contexto, a mulher ocupa apenas as posições de liderança cedidas pelos homens, com base em imagens femininas estereotipadas, comumente ligadas à criação e ao ensino.

\section{O modelo de trabalho dos aplicativos de mobilidade urbana}

A economia de compartilhamento surge na década de 1990, nos Estados Unidos, viabilizando o surgimento e a expansão de novos modelos de negócios. Consiste em um tipo específico de economia colaborativa de consumo, por meio da qual recursos são compartilhados por pessoas e organizações, e intermediados por uma plataforma on-line (Botsman, 2013; Franco \& Ferraz, 2019). É também conhecida como economia colaborativa, crowd-employment (crowd-working), gig economy, on-demand economy, mobile labour markets (MLMs), dentre outros (Codagnone et al., 2016).

Apesar de divergências quanto ao enquadramento dos aplicativos de mobilidade urbana como parte da economia de compartilhamento, entende-se que o modelo negocial opera por meio de cadastro do motorista devidamente habilitado e com automóvel de sua propriedade ou não, na plataforma on-line, mediante adesão unilateral às regras e políticas da empresa, e monitoramento pautado em avaliações e comentários dos usuários, a fim de que se mantenha um padrão de desempenho satisfatório definido para o atendimento aos clientes (De Stefano, 2016; Franco \& Ferraz, 2019).

O primeiro aplicativo de mobilidade urbana, a empresa Uber, surge em 2009, nos Estados Unidos, com a proposta de permitir o trabalho freelance de motoristas, no atendimento de passageiros em potencial. Esse modelo de negócio acaba tornando-se um fenômeno global, com elevado valor de mercado e receptividade mundial (Zanatta et al., 2017).

No Brasil, a empresa Uber foi introduzida em 2014, sendo posteriormente criadas outras plataformas de transporte (99POP, Cruzeiro Go, Mobbi, Uai Move etc.), sendo algumas delas destinadas exclusivamente ao público feminino (Venuxx). O modelo de trabalho oferecido torna-se particularmente atrativo e viável em um contexto de crise econômica, sobretudo para aqueles com dificuldade de inserção no mercado formal de trabalho (Franco \& Ferraz, 2019; Peticca-Harris et al., 2018; Zanatta et al., 2017). É esse o caso das mulheres, cuja entrada no mercado de trabalho sempre foi mais difícil, especialmente em função dos obstáculos sociais e culturais enfrentados, como o assédio moral e sexual, a desqualificação e a diferença salarial (Gomes, 2019). Assim, nesse contexto de desigualdade de gênero, o modelo inovador e simples dos aplicativos de mobilidade urbana torna-se ferramenta útil que facilita às mulheres o exercício da profissão de motorista, considerada tipicamente masculina (Beigi et al., 2020; Scheller, 2009). 


\section{A profissão de motoristas de aplicativos de transporte}

A profissão de motorista de aplicativo de transporte, apesar de recente, tornou-se atrativa também para mulheres, particularmente pela facilidade de adesão na plataforma on-line e pela proposta de flexibilidade, liberdade e ganhos financeiros (Beigi et al., 2020; Franco \& Ferraz, 2019). Outro fator a ser considerado consiste na dupla jornada de trabalho da mulher, que encontra na flexibilidade da profissão uma forma de exercer o trabalho doméstico e o trabalho remunerado (Siqueira, 2016), e ainda suprir a necessidade financeira e o anseio pela independência econômica (Ávila \& Ferreira, 2014).

O trabalho remunerado revela-se apto a aumentar a capacidade de voz e autoestima da mulher, que passa a ter maior liberdade e motivação para progredir (Kabeer, 2013; Melo, 2018). No entanto, ainda que todos esses fatores tenham contribuído para um aumento da presença feminina no setor, a atuação ainda é tímida, dada a existência de estereótipos femininos ligados ao exercício da profissão de motorista e ao próprio ato de dirigir (Yeung \& Von Hippel, 2008), mas principalmente por questões de segurança (Wright, 2014). Nesse sentido, o medo de assédio e de violência física e psicológica resulta na preferência das motoristas pelo atendimento de mulheres passageiras, bem como pela escolha de atuação durante o dia e em bairros considerados menos perigosos (Beigi et al., 2020).

\section{PROCEDIMENTO METODOLÓGICO}

O estudo realizado consistiu em uma pesquisa do tipo descritiva (Gil, 2008) e de abordagem qualitativa (Godoy, 1995) e interpretativa (Crotty, 1998), conforme os objetivos delineados para este trabalho.

A unidade de análise correspondeu à percepção de mulheres motoristas de aplicativos de transporte quanto às relações de gênero e às particularidades do contexto socioeconômico e cultural brasileiro em seu cotidiano de trabalho. A unidade de observação constituiu-se pelo trabalho de motorista de aplicativo de mobilidade urbana das entrevistadas.

Os sujeitos da pesquisa foram 11 mulheres motoristas de aplicativos de mobilidade urbana, atuantes em pelo menos uma plataforma (Uber, 99POP, Venuxx, Cruzeiro Go, Mobbi, Uai Move) na região metropolitana de Belo Horizonte, Minas Gerais. As participantes da pesquisa foram nomeadas pela letra " $E$ ", abreviatura de entrevistada, e numeradas sequencialmente, de E1 a E11.

As mulheres, entrevistadas no final do ano de 2019, estão na faixa etária entre 23 e 56 anos. Quanto ao estado civil, quatro entrevistadas são solteiras, três são casadas, duas são divorciadas, uma é viúva e uma vive em união estável. No que tange ao nível de escolaridade, oito têm curso superior completo, sendo duas com especialização/MBA, duas têm curso superior incompleto e uma concluiu o ensino médio. No que se refere ao tempo de atuação profissional, as entrevistadas estão cadastradas há pelo menos seis meses nas plataformas de aplicativos de transporte, estando a motorista com mais tempo de atuação exercendo a atividade há três anos e quatro meses na Uber, conforme sintetizado no Quadro 1 a seguir. 
Quadro 1

Perfil sociodemográfico do grupo pesquisado

\begin{tabular}{|c|c|c|c|c|c|}
\hline Entrevistadas & Idade & Estado Civil & Grau de Instrução & $\begin{array}{l}\text { Plataforma on-line } \\
\text { de atuação }\end{array}$ & $\begin{array}{l}\text { Tempo na } \\
\text { Plataforma }\end{array}$ \\
\hline E1 & 46 anos & Divorciada & Superior Incompleto & Uber e 99Pop & 7 meses \\
\hline E2 & 39 anos & Casada & $\begin{array}{c}\text { Superior Completo - } \\
\text { Pedagogia }\end{array}$ & 99Pop, Uber e Vapt & 9 meses \\
\hline E3 & 33 anos & Casada & $\begin{array}{c}\text { Superior Completo - } \\
\text { Administração Especialização } \\
\text { em Agronegócio em curso }\end{array}$ & Uber e 99Pop & 1 ano \\
\hline E4 & 56 anos & Divorciada & $\begin{array}{c}\text { Superior Completo - } \\
\text { Matemática e Designer de } \\
\text { Interiores }\end{array}$ & Uber & $\begin{array}{l}3 \text { anos e } \\
4 \text { meses }\end{array}$ \\
\hline E5 & 52 anos & Solteira & Superior Completo & Uber e 99Pop & 2 anos \\
\hline E6 & 50 anos & Solteira & Superior Incompleto & $\begin{array}{l}\text { Uber, 99Pop, } \\
\text { Venuxx e Mobbi }\end{array}$ & 2 anos \\
\hline E7 & 45 anos & Solteira & $\begin{array}{c}\text { Superior Completo - } \\
\text { Publicidade }\end{array}$ & Uber e 99Pop & 1 ano \\
\hline E8 & 40 anos & Viúva & $\begin{array}{c}\text { Superior Completo - } \\
\text { Educação Física; MBA em } \\
\text { Gestão Comercial e Vendas }\end{array}$ & Uber & 1 ano \\
\hline E9 & 23 anos & Solteira & $\begin{array}{c}\text { Superior em Curso - } \\
\text { Engenharia Civil }\end{array}$ & Uber e 99Pop & 7 meses \\
\hline E10 & 31 anos & $\begin{array}{l}\text { União } \\
\text { Estável }\end{array}$ & $\begin{array}{c}\text { Superior Completo - } \\
\text { Turismo }\end{array}$ & $\begin{array}{l}\text { Uber, 99Pop, Venuxx, } \\
\text { Cruzeiro Go e Uai Move }\end{array}$ & 2 anos \\
\hline E11 & 29 anos & Casada & Ensino Médio Completo & Uber e 99Pop & 6 meses \\
\hline
\end{tabular}

Fonte: Elaborado pelos autores.

As entrevistadas foram escolhidas pelo critério de acessibilidade e pela indicação de participantes pesquisadas, utilizando-se, dessa forma, da técnica denominada "bola de neve", que emprega cadeias de referência (Vinuto, 2014). Quanto ao número de entrevistadas para esta pesquisa, adotou-se o critério da saturação, criado por Glaser e Strauss (1967) para descrever o momento em que os dados coletados não mais fornecem novas informações para o estudo, ou fornecem poucos dados para subsidiar ou aprofundar a pesquisa (Fontanella et al., 2011; Minayo, 2017), o que aconteceu na décima primeira entrevista. Com base nessa definição, foram entrevistadas 11 mulheres, número que também se adéqua ao critério quantitativo de participantes adotado por Atran, Medin e Ross (2005).

As entrevistas foram realizadas com base em um roteiro semiestruturado elaborado em conformidade com o objetivo desta pesquisa. As entrevistas foram gravadas, transcritas e o conteúdo foi agrupado e categorizado por meio de uma tabulação qualitativa, caracterizada pela elaboração de tabelas segundo o tema das perguntas constantes do roteiro desenvolvido.

Os dados coletados foram tratados por meio da técnica da análise de conteúdo (Franco, 2008), considerados os aportes trazidos pelos trabalhos de Melo $(2012,2018)$. As questões tabuladas emergiram dos discursos do grupo pesquisado e foram distribuídas para serem analisadas considerando a concepção de gênero de Scott (1995), a perspectiva da mulher vítima da dominação masculina e violência simbólica de Bourdieu (2002) e a percepção da mulher sujeito de transformação social de Touraine (2007). 


\section{RESULTADOS E ANÁLISES}

A análise dos dados desta pesquisa foi realizada considerando as relações de gênero e o contexto socioeconômico e cultural brasileiro no ambiente de trabalho, a dominação masculina e a violência simbólica na atuação profissional das entrevistadas e a sua percepção como sujeitos de transformação social.

\section{As relações de gênero no ambiente de trabalho e o contexto socioeconômico e cultural brasileiro}

Scott (1995) concebe o gênero como forma de articulação do poder e como elemento das relações sociais histórica e culturalmente construídas. Nessa perspectiva, o contexto socioeconômico e cultural contribui para a reprodução e permanência de estereótipos que promovem desigualdades entre homens e mulheres, tanto na esfera privada quanto na pública. A divisão do trabalho em atividades masculinas e femininas acaba sendo incorporada às estruturas sociais o que, no Brasil, ocorreu por meio da reestruturação do modelo aristocrático da família patriarcal delineado no período colonial (Alves \& Castro, 2018; Fenili, 2016; Pinto et al., 2014). Nesse sentido, a maioria das entrevistadas considerou a profissão de motorista predominantemente masculina, corroborando o entendimento de Beigi et al. (2020) e Scheller (2009). No entanto, algumas entrevistadas têm percebido um aumento da presença de mulheres atuantes nos aplicativos de mobilidade urbana.

Ela é predominantemente masculina, embora o mercado tenha tido uma aderência às mulheres bastante grande $[\ldots](\mathrm{E} 1)$.

Ainda acho que é predominantemente masculina [...]. Mas está melhorando, está aumentando o número de mulheres (E6).

[...] culturalmente é uma profissão masculina, então ainda há uma resistência das pessoas [...] (E7).

Ainda que considerada predominantemente masculina, tal fator não foi obstáculo para que essas mulheres exercessem a profissão, cuja escolha ocorreu, sobretudo, em razão da crise econômica brasileira e da dificuldade de inserção no mercado formal de trabalho, corroborando Beigi et al. (2020), Franco e Ferraz (2019) e Peticca-Harris et al. (2018).

Por causa da crise do nosso país, o desemprego está muito alto, a taxa, o índice de desemprego é muito alto e eu faço parte dessa... desse índice. Então, dirigir o aplicativo é uma saída, não é uma opção ou uma escolha. É apenas uma saída (E7).

Só que eu creio que com o decorrer, né, desse desemprego que o país tá sofrendo, vai aumentar o volume de motoristas mulheres (E8).

Todavia, a profissão também se mostrou atrativa pela flexibilidade da atividade, que permite às mulheres exercerem um trabalho remunerado juntamente com o trabalho doméstico e cuidado com a família (Beigi et al., 2020; Franco \& Ferraz, 2019; Peticca-Harris et al., 2018; Siqueira, 2016).

Por estar mais perto da minha família, é....podendo fazer meu horário (E2).

[...] é ter a flexibilidade de trabalhar nos horários que eu posso, que eu quero, claro, dentro das minhas metas diárias financeiras [...] significa uma independência financeira ainda maior, uma liberdade [...] (E11).

Outro fator comumente citado pelas entrevistadas foi a necessidade de sustento familiar ou de complementação da renda, dados os baixos salários no mercado formal (Gomes, 2019; Valente et al., 2019). A maioria das entrevistadas afirma que o exercício da profissão não consiste em uma realização pessoal, mas fonte de renda, conforme constante nos extratos de suas entrevistas e corroborando os achados de Peticca-Harris et al. (2018).

Realização pessoal não. Mas eu considero que é um trabalho que me dá uma renda conforme eu trabalhe né, ou não, e que me dá a liberdade de horário (E6).

[...] ser motorista de aplicativo não é ter uma realização profissional. É mesmo para complemento de renda ou para pessoas que estão desempregadas não ficarem ociosas em casa e terem uma fonte de renda [...] (E9). 
No que tange à dimensão econômica das entrevistadas (Melo, 2012, 2018), constatou-se que o trabalho como motorista de aplicativo permitiu à maioria das entrevistadas se tornar financeiramente independente atuando exclusivamente nessa função. Dessa forma, verifica-se como a independência financeira contribui para que mulheres conquistem espaço e autonomia, sendo parcial ou totalmente responsáveis pelo pagamento de despesas domésticas e pessoais (Ávila \& Ferreira, 2014; Melo, 2012, 2018).

O contexto cultural, assim como o econômico possuem importante papel no fortalecimento de estruturas sociais e na reprodução de atos e comportamentos, contribuindo para diferenciações entre homens e mulheres e para a organização das relações de poder (Bourdieu, 2002; Scott, 1995). No Brasil, tendo as relações de gênero sido configuradas com base em um sistema patriarcal e desigual, verifica-se a sua reprodução nas esferas do trabalho, da política e da economia (Fenili, 2016; Pinto et al., 2014). As entrevistadas revelam a presença de uma cultura brasileira machista, na qual a figura da mulher motorista ainda é rejeitada, vista com desconfiança e considerada menos competente que o homem (Yeung \& Von Hippel, 2008). No entanto, destacam certas mudanças, verificadas pelo aumento de mulheres no exercício da profissão e maior aceitação social, conforme conteúdo de suas falas.

Principalmente pelo quesito machismo na sociedade, né? Em que se acredita que mulher que dirige mal, né? A expressão é... "mulher atrás do volante, perigo constante" [...] (E3).

[...] Acho que está abrindo a cabeça da sociedade. As pessoas estão aceitando. Os tempos estão mudando. [...] as coisas estão ficando mais acessíveis e as pessoas estão aceitando melhor as mudanças que estão acontecendo (E7).

A cultura brasileira eu acho que é aquela coisa, né, que só os homens deveriam trabalhar como motoristas e tal, né, isso aí já vem de anos e anos atrás. Mas eu acho que de um tempo para cá é.... eles têm mudado essa percepção um pouco [...] (E11).

Não obstante inseridas em um contexto cultural machista e desigual (Bourdieu, 2002), as entrevistadas reconhecem sua competência profissional, mostrando-se confiantes e capazes para o exercício da profissão (Touraine, 2007), coincidindo com os resultados de Beigi et al. (2020).

Me acho uma boa motorista. Eu acho que eu trabalho bem, eu dirijo bem [...] (E6).

Que eu sou uma boa motorista, que eu sou atenta, que eu sou respeitosa no trânsito (E9).

Ademais, a maior confiança e autonomia das participantes para a atuação profissional pode estar relacionada ao fato de apresentarem um nível mais elevado de escolaridade, já que a educação constitui meio de emancipação, redução das diferenças e promoção de transformações sociais e culturais (Gomes, 2019; Melo, 2018; Telles, 2013; Tozetti et al., 2016).

\section{A dominação masculina e a violência simbólica na atuação profissional das entrevistadas}

Segundo Bourdieu (2002), a ordem social construída com base em uma visão androcêntrica e naturalmente justificada pelas diferenças biológicas entre os sexos impõe uma divisão sexual do trabalho, separando os espaços reservados a homens e mulheres e legitimando a dominação masculina. $O$ autor entende que as estruturas de dominação seriam produzidas e reproduzidas a ponto de serem percebidas como naturais pelo dominado e, não obstante barreiras tenham sido superadas pelas conquistas femininas, as mulheres permaneceriam vítimas de um sistema arbitrário que as oprime, ainda que invisível e silenciosamente. A existência de preconceito com mulheres motoristas e a naturalização da dominação foram observadas em alguns extratos das entrevistas.

[...] É natural que mais homens dirijam do que as mulheres (E3).

O que atrapalha o trabalho da gente que a gente acha é esse negócio, esse fato de a gente ser mulher, a gente é discriminada por outros motoristas, né. Querendo ou não, eles não ficam felizes de saber que a gente está ocupando o lugar deles, não. Eles acham que o lugar é deles. [...] O que dificulta tudo sempre, sempre é o preconceito [...] (E4). 
No entanto, ainda que percebam certo preconceito, apenas duas entrevistadas disseram ter sofrido, diretamente, algum tipo de discriminação, o que reforça a ideia de uma violência simbólica, invisível e por vezes velada (Bourdieu, 2002).

Quanto ao funcionamento das plataformas de mobilidade urbana, apesar de mais da metade das entrevistadas reconhecer a existência de uma dominação masculina (Bourdieu, 2002) no exercício da profissão de motorista de aplicativo de transporte, todas consideram que o acesso às plataformas de mobilidade urbana se dá de forma igualitária entre homens e mulheres, com igualdade de oportunidades para ambos os sexos. No entanto, quando perguntadas sobre a existência de uma hierarquia na plataforma, sete entrevistadas responderam haver uma hierarquia conforme o número de corridas realizadas. Assim, quanto maior o número de corridas feitas pelo motorista e boas avaliações recebidas dos usuários, maiores os ganhos financeiros e os privilégios concedidos pela empresa.

Com base na análise do funcionamento do modelo dos aplicativos de transporte, verifica-se que o crescimento profissional do motorista depende do número de corridas realizadas em determinados horários e da avaliação subjetiva dos passageiros (Franco \& Ferraz, 2019; Peticca-Harris et al., 2018). Nesse cenário, observa-se que a mulher acaba prejudicada pelas seguintes razões: dificuldade de realização de maior quantidade de corridas, restringidas pela dupla jornada de trabalho e, principalmente, pelo medo de dirigir em determinados locais e horários, devido à falta de segurança (Beigi et al., 2020; Wright, 2014); além do risco de recebimento de notas baixas/ruins exclusivamente pelo fato de serem mulheres. É o que se extrai das falas de entrevistadas:

[...] minha vontade era trabalhar à noite e eu tenho medo de trabalhar à noite, inclusive quando eu comecei, eu trabalhava [...] aí parei e comecei, mas eu preferia se pudesse e tivesse segurança, eu gostaria de trabalhar na parte da noite (E4).

[...] o que dificulta é não ter coragem para trabalhar nos horários de maior pico, onde teria rendimentos ainda maiores, em menor tempo, por questões de medo, e de riscos de assalto, de violência e algo do tipo (E11).

No caso de discriminação de gênero, o sistema de avaliações dos aplicativos se revela inapto a coibir manifestações de preconceitos de certos usuários que reproduzem pensamentos e comportamentos próprios de estruturas sociais marcadas pela dominação masculina. Identifica-se aqui, novamente, a presença da chamada violência simbólica tratada por Bourdieu (2002), uma vez que as mulheres motoristas, ainda que de maneira imperceptível, são vítimas de uma plataforma de trabalho que, "invisivelmente", reflete a estrutura patriarcal e machista da sociedade brasileira.

Ao tratar da influência familiar, Bourdieu (2002) aponta como a instituição família possui importante papel na incorporação de comportamentos, valores e percepções. O modelo aristocrático da família brasileira, ao reproduzir conceitos de desigualdade de gênero, reforça a ideia da existência de profissões masculinas e femininas. Nessa perspectiva, a profissão de motorista, tradicionalmente masculina (Beigi et al., 2020; Scheller, 2009), não seria atividade a ser incentivada para a prática feminina. É o que se observou quando oito entrevistadas afirmaram não ter tido nenhuma influência familiar para o exercício dessa profissão.

Com base na análise dos pressupostos de Bourdieu (2002), notou-se que a inserção da mulher em um ambiente de atuação predominantemente masculino ainda lhe traz desvantagens, mesmo que de maneira sutil. Assim, não obstante barreiras estejam sendo rompidas e haja um crescimento da presença feminina como motorista de aplicativos de transporte, a mulher ainda permanece vítima de um sistema de dominação simbólica e do contexto socioeconômico e cultural no qual está inserida. 


\section{As entrevistadas como sujeito de transformação social}

Conforme Touraine (2007), a mulher sujeito de transformação social existe na medida em que ela não se percebe como vítima de uma sociedade hierarquizada e desigual, mas como agente de sua própria história, capaz de promover significativas mudanças estruturais. É possível observar que as entrevistadas, apesar de reconhecerem as dificuldades impostas pela cultura brasileira machista e pela falta de segurança para o exercício da atividade profissional, não se percebem como vítimas dessa estrutura social. Ao contrário, percebem-se profissionais competentes, boas motoristas (Beigi et al., 2020), corajosas, exercendo um trabalho como outro qualquer, conforme pode ser observado nos trechos a seguir.

[...] para falar a verdade, eu não tenho medo de nada não, né, e.... eu vou na fé e vou embora. Sou forte, não me intimido, né, não me intimido com quem entra, com quem não entra [...] (E4).

Me acho uma boa motorista. Eu acho que eu trabalho bem, eu dirijo bem, ainda mais que eu tenho formação disso né, no trânsito, como eu já tinha falado antes (E6).

Bom, minha percepção é o seguinte: sou, eu me considero uma boa motorista [...] (E7).

A mulher sujeito de transformação (Touraine, 2007) também se fez presente na fala de todas as entrevistadas quando afirmaram possuir características que trazem um diferencial positivo ao exercício da profissão.

[...] nós somos mais tranquilas no trânsito, temos mais cuidado, mais atenção, tratamos os passageiros com mais educação, somos mais sensíveis (E9).

Sim, eu acho que as mulheres trazem um diferencial sim para a profissão. [...] Mas, na minha opinião, é que nós, mulheres, a gente é mais paciente, a gente é mais observadora [...] A gente é mais cautelosa no trânsito, tem mais cuidado, dirige de forma mais atenciosa (E11).

É interessante notar que as mesmas características por vezes usadas para inferiorizar a mulher (gentileza, atenção, sensibilidade, cuidado, educação), são aqui ressignificadas e vistas como qualidades que as tornam melhores profissionais.

Do mesmo modo, o fato de a maioria das entrevistadas não mudar o seu comportamento para serem respeitadas profissionalmente, demonstra autonomia e confiança, indo de encontro aos achados de Beigi et al. (2020), que verificaram a adoção de comportamentos considerados masculinos por mulheres motoristas para se protegerem e serem respeitadas. Novamente, os dados obtidos podem estar relacionados à formação acadêmica das entrevistadas, uma vez que a educação constitui importante meio de emancipação e empoderamento das mulheres (Melo, 2012, 2018).

Não, não mudei em nada para ser respeitada. Nada (E6).

Não, eu não mudei, não, porque eu já sou uma pessoa com uma postura bem definida (E7).

Ainda é possível extrair do conteúdo das entrevistas, analisado com base na percepção de Touraine (2007) sobre a mulher, que as entrevistadas, a partir do momento em que se percebem sujeitos de construção de sua própria identidade, não se veem como vítimas, mas inteiramente capazes de conquistar sua autonomia financeira, sem necessidade de adequação às estruturas sociais preestabelecidas e organizadas para inferiorizá-las.

Ser motorista de aplicativo para mim é uma oportunidade, é um desafio [...]. Ela significa meu sustento, significa me manter ocupada, me manter focada. Significa para mim também um lazer, tá? E também... uma forma de manter meu amor próprio e minha autoestima também em dia (E1).

Ser motorista de aplicativo é a minha independência financeira, é ser o meu alívio de estresse [...] eu gosto de ser motorista de aplicativo, por incrível que pareça, entendeu? Eu gosto, sei lá, é... têm os lados bons e ruins, ela é tudo para mim (risos) (E10).

Ser motorista de aplicativo para mim é uma sensação de liberdade, uma sensação de poder estar em vários lugares, cada momento, cada hora está num lugar. É bom você estar conhecendo pessoas novas, cada dia enfrentando um tipo de situação, conhecendo as histórias das pessoas [...] (E11). 
Melo $(2012,2018)$ corrobora esse entendimento ao evidenciar como as dimensões cognitivo-analítica (formação educacional e competência profissional), subjetiva (autoestima e autoconfiança), econômica (independência financeira), social (família), política e cultural (relações de poder na sociedade) favorecem o processo de empoderamento da mulher como sujeito e como profissional, consideradas as particularidades de cada contexto.

\section{CONSIDERAÇÕES FINAIS}

Este estudo abordou a forma como as relações de gênero e o contexto socioeconômico e cultural brasileiro são percebidos por mulheres motoristas de aplicativos de mobilidade urbana em sua atuação profissional, utilizando-se, para tanto, da concepção de gênero de Scott (1995), dos pressupostos teóricos de dominação masculina e de violência simbólica de Bourdieu (2002) e da percepção da mulher como sujeito de transformação do campo social e cultural de Touraine (2007).

A pesquisa realizada permitiu constatar como o gênero, constitutivo das relações sociais e reflexo das relações de poder, deve ser compreendido, considerando-se o contexto social, econômico, histórico e cultural. Ao analisar as particularidades da sociedade brasileira, observou-se o reconhecimento, pelas mulheres motoristas, da existência de um ambiente de trabalho masculinizado e de uma cultura patriarcal e machista, o que de certa forma revelou-se um obstáculo para a sua atuação profissional.

No entanto, as motoristas participantes não se enxergaram ou se descreveram como vítimas de um modelo hegemônico de dominação masculina, mas como mulheres confiantes, boas motoristas, em busca de independência financeira. Assim, mesmo com as dificuldades da profissão, essas mulheres podem ser vistas como sujeitos de transformação social e cultural, agentes de suas vidas e construtoras de sua própria realidade. Nesse sentido, o trabalho remunerado revela-se instrumento apto a aumentar a capacidade de voz e autoestima da mulher que passa a ter maior liberdade e motivação para alcançar a sua autonomia.

Considerando o contexto brasileiro de crise econômica e de insegurança financeira, observa-se a convergência de mulheres de diferentes áreas de formação e circunstâncias pessoais e sociais distintas para a utilização de plataformas de mobilidade urbana como forma de assegurar, manter ou até mesmo conquistar a independência financeira. No entanto, apesar de o desfavorável cenário econômico figurar como fator principal de escolha das entrevistadas pela profissão, constatou-se que a facilidade de adesão a esse modelo de trabalho, a flexibilidade de horários e o fato de a atividade ser altamente individualizante também favoreceram essa escolha.

No que tange à flexibilidade de horários apontada pela maioria das entrevistadas, verificou-se que, por medo de violência e assédio, foram desenvolvidas estratégias de segurança e de menor exposição a situações de risco. Para tanto, algumas motoristas limitaram a sua atuação profissional a determinados períodos do dia, priorizando regiões consideradas seguras e o atendimento exclusivo ou preferencial a passageiras mulheres. Essa constatação demonstra como o gênero impacta no exercício da atividade, criando barreiras estruturais a maiores ganhos financeiros (mais horas de corrida) e ao progresso na carreira.

Observou-se ainda que o grau de escolaridade das entrevistadas pode constituir um fator de emancipação, já que a educação confere às mulheres maior liberdade de decisão e de atuação nos diversos campos sociais.

Quanto ao acesso às plataformas de aplicativos de transporte e às oportunidades para homens e mulheres no ambiente de trabalho, verificou-se que, apesar de todas as entrevistadas acreditarem na igualdade de acesso e oportunidades, o sistema subjetivo de avaliações dos aplicativos não é capaz de filtrar ou coibir eventuais notas baixas dadas às motoristas unicamente pelo fato de serem mulheres. Assim, notou-se que, permanecendo inseridas em um meio predominantemente masculino, as mulheres motoristas, ainda que de maneira imperceptível ou invisível, se mantêm vítimas de uma dominação e violência simbólicas. Trata-se da perpetuação, ainda que invisível, dos estereótipos e desigualdades de gênero por meio de estruturas legitimadas como naturais, em um mundo onde a mulher continua definida pelo olhar masculino. Com isso, verifica-se a necessidade de adequação dos aplicativos de mobilidade urbana ao contexto socioeconômico e cultural do país, de modo a garantir maior proteção e mecanismos de apoio aos grupos comumente desfavorecidos por esse contexto, como o das mulheres motoristas. 
Por fim, constatou-se que o exercício da profissão de motorista de aplicativo de transporte por mulheres constitui forma de empoderamento feminino nas dimensões social, econômica, política e cultural, desde o momento em que as entrevistadas se mostram agentes capazes de romper os preconceitos e estruturas sociais, a fim de alcançar reconhecimento, autonomia e independência financeira, até quando reconhecem a existência de obstáculos provenientes de uma sociedade brasileira que, não obstante machista e historicamente aristocrata, patriarcal e escravocrata, se encontra em processo de mudança e de maior aceitação de mulheres atuando na profissão de motorista.

Registra-se como principal contribuição teórica deste estudo a constatação de que as relações de gênero, com destaque na inserção das mulheres no mercado de trabalho e profissional, não podem ser colocadas em um posicionamento linear de exclusão caracterizada pela dominação masculina - violência simbólica - teto de vidro - empoderamento, o que é apontado na maioria dos estudos sobre o tema.

Os olhares teóricos apontam para novas direções: apesar de as mulheres serem atingidas pelas desigualdades e violência, elas se julgam mais livres do que dependentes e mais responsáveis do que submissas. Os posicionamentos das entrevistadas possuem uma perspectiva mais cultural do que social, de modo que se definem em relação a si próprias, com o objetivo da construção de si mesmas.

Entre as limitações do estudo, destaca-se o fato de ter sido realizado apenas com motoristas mulheres de aplicativos de transporte atuantes na região metropolitana de Belo Horizonte, podendo ser aplicado a outras regiões do Brasil. Além disso, por se tratar de uma pesquisa que envolve variáveis complexas, sugere-se um maior aprofundamento, para estruturação teórica mais sólida a partir das evidências apontadas na pesquisa. 


\section{REFERÊNCIAS}

Abramo, L., \& Valenzuela, M. E. (2016). Tempo de trabalho remunerado e não remunerado na América Latina: uma repartição desigual. In A. R. P. Abreu, H. Hirata, \& M. R. Lombardi (Org.), Gênero e trabalho no Brasil e na França: perspectivas interseccionais (Cap. 9, pp. 113-123). São Paulo, SP: Boitempo.

Alves, C. M., \& Castro, J. G. O. (2018). De Domingas à Dinaura: silenciamentos e resistências nos discursos feministas em Hatoum. Revista interdisciplinar em cultura e sociedade, 4(especial), 371-382.

Amorim, J. M. M. (2015). Mulher e o mundo do trabalho: histórias de vida de estudantes no programa nacional mulheres mil - Instituto Federal de Educação, Ciência e Tecnologia do Tocantins - IFTO (Dissertação de Mestrado). Universidade Federal de Santa Maria, Santa Maria, RS.

Antunes, P. P. S. (2010). Travestis envelhecem? (Dissertação de Mestrado). Pontifícia Universidade Católica de São Paulo, São Paulo, SP.

Atran, S., Medin, D. L., \& Ross, N. O. (2005). The cultural mind: Environmental decision makingand cultural modeling within and across populations. Psychological Review, 112(4), 744-776.

Ávila, M. B. M., \& Ferreira, V. M. (2014). Trabalho produtivo e reprodutivo no cotidiano das mulheres brasileiras. In M. B. M. Avila, \& V. M. Ferreira (Orgs.), Trabalho remunerado e trabalho doméstico no cotidiano das mulheres (Art. 2, pp. 13-49). Recife, PE: SOS CORPO Instituto Feminista para a democracia.

Beigi, M., Nayyeri, S., \& Shirmohammadi, M. (2020). Driving a career in Tehran: Experiences of female internet taxi drivers. Journal of Vocational Behavior, 116(Part A), 103347.

Biroli, F., \& Miguel, L. F. (2012). Teoria política e feminismo: abordagens brasileiras. Vinhedos, RS: Horizonte.

Bogéa, A. F. (2017). Um olhar sobre o gênero: categoria analítica e questões sócio-políticas. In Anais do VIII Jornada Internacional Políticas Públicas, São Luís, MA.

Botsman, R. (2013, novembro 21). The Sharing Economy Lacks a Shared Definition. Recuperado de https://www.fastcompany.com/3022028/ the-sharing-economy-lacks-a-shared-definition

Bourdieu, P. (2002). A Dominação Masculina. Rio de Janeiro, RJ: Betrand Brasil.

Codagnone, C. Abadie, F., \& Biagi, F. (2016). The Future of Work in the "Sharing Economy": market efficiency and equitable opportunities or unfair precarisation? (JRC Science for Policy Report). Sevilha, España: Institute for Prospective Technological Studies.

Crotty, M. (1998). The foundation of social research: meaning and perspective in the research process. London, UK: Sage.

De Stefano, V. (2016). The rise of the "just-in-time workforce": On-demand work, crowdwork and labour protection in the "gig-economy". Conditions of work and employment series, 71, 485-489.

De Souza, E., Baldwin, J. R., \& Rosa, F. H. (2000). A construção social dos papéis sexuais femininos. Psicol. Reflex. Crit., 13(3), 485-496.

Fallavena, L. H. A. (2017). Agora é que são elas: trajetória de carreiras de mulheres motoristas de aplicativos de transportes (Trabalho de conclusão de curso). Universidade Federal do Rio Grande do Sul, Porto Alegre, RS.

Fenili, R. R. (2016). Desempenho em processos de compras e contratações públicas: um estudo a partir da inovação e das práticas organizacionais (Tese de Doutorado). Universidade de Brasília, Brasília, DF.

Fontana, E., \& Costa, M. M. A. (2016). A nova mulher em uma nova comunidade: um recorte entre as comunidades tradicionais e as sociedades atuais em matéria de gênero. Revista Novos Estudos Jurídicos, 21(1), 182-214.

Fontanella, B. J. B., Luchesi, B. M., Saidel, M. G. B., Ricas, J., Turato, E. R., \& Melo, D. G. (2011). Amostragem em pesquisas qualitativas: proposta de procedimentos para constatar saturação teórica. Cad. Saúde Pública, 27(2), 388-394.

Franco, D. S., \& Ferraz, D. L. S. (2019). Uberização do trabalho e acumulação capitalista. Cad. EBAPE.BR, 17(spe), 844-856.

Franco, M. L. P. B. (2008). Análise de conteúdo. Brasília, DF: Líber Livro.

Gil, A. C. (2008). Métodos e técnicas de pesquisa social. São Paulo, SP: Atlas.

Glaser, B., \& Strauss, A. (1967). The discovery of grounded theory: strategies for qualitative research. New York, NY: Aldine Publishing Company.

Godoy, A. S. (1995). Pesquisa qualitativa: tipos fundamentais. Revista de Administração de Empresas, 35(3), 20-29.

Gomes, C. T. M. (2019). Análise de políticas para a efetivação do princípio da igualdade de remuneração em razão do gênero no Brasil (Dissertação de Mestrado). Universidade de Fortaleza, Fortaleza, CE.

Kabeer, N. (2013). Contextualizando as trilhas econômicas do empoderamento de mulheres: resultados de um programa de pesquisa em diferentes países. Revista feminismos, 1(2), 1-28.

Louro, G. L. (2004). Gênero, sexualidade e educação: uma perspectiva pós-estruturalista. Petrópolis, RJ: Vozes.

Louro, G. L. (2008). Gênero e sexualidades: pedagogias contemporâneas. ProPosições, 19(2), 17-23.

Melo, M. C. O. L. (2012). Mulheres gerentes entre o empoderamento e o teto de vidro. In M. E. Freitas, \& M. Dantas (Org.), Diversidade sexual e trabalho. São Paulo, SP: Cengage Learning.

Melo, M. C. O. L. (2018) Mulheres gerentes entre o empoderamento e o teto de vidro. In A. Carvalho, Neto, \& F. Versiani (Org.), Mulheres profissionais - Quem é o sexo frágil?. Belo Horizonte, MG: PUCMINAS.

Mendes, M. A. (2005). Mulheres chefes de família em áreas Zeis: gênero, poder e trabalho (Tese de Doutorado). Universidade Federal de Pernambuco, Recife, PE.

Mészáros, I. (2008). A educação para além do capital. São Paulo, SP: Boitempo.

Minayo, M. C. S. (2017). Amostragem e saturação em pesquisa qualitativa: consensos e controvérsias. Revista Pesquisa Qualitativa, 5(7), 1-12. 
Nogueira, S., \& Castelhano, J. (2012). Gestão dos tempos e do percurso profissional: estratégias das mulheres em profissões definidas no masculino. Laboreal, 8(1), 42-55.

Peticca-Harris, A., Degama, N., \& Ravishankar, M. N. (2018). Postcapitalist precarious work and those in the 'drivers' seat: exploring the motivations and lived experiences of Uber drivers in Canada. Organization, 27(1), 36-59.

Pinto, A., Nunes, S. M., \& Fazenda, R. (2014). Um estudo sobre a influência do gênero em funções tradicionalmente masculinas e femininas. International Journal on Working Conditions, 7, 17-33.

Prado, V.M., Di Giorgi, C.A.G., \& Ribeiro, A. I. M. (2015). Identidade e gênero: reflexões sobre feminismos e pensamento da Alain Touraine. In Brabo, T. S. A. M. (Org.), Mulheres, gênero e violência (Cap. 4, pp. 73-96) São Paulo, SP: Cultura Acadêmica.

Scheller, L. (2009). Le temps des conductrices de bus. Pour un espace de pensée entre activité professionnelle et personnelle. Temporalités, 9, 1-15.

Scott, J. (1995). Gênero: uma categoria útil para a análise histórica. Educação e Realidade, Porto Alegre, 20(2), 71-99.

Silva, E. R. (2011). As mulheres no trabalho e o trabalho das mulheres: um estudo sobre as mulheres fumageiras do Recôncavo Baiano (Tese de Doutorado). Universidade Federal da Bahia, Salvador, BH.

Silva, S. M. C. (2016). Tetos de vitrais: gênero e raça na contabilidade no Brasil (Tese de Doutorado). Universidade de São Paulo, São Paulo, SP.

Siqueira, O. M. (2016). A dupla jornada de trabalho feminino: realidade, implicações e perspectivas (Dissertação de Mestrado). Pontifícia Universidade Católica de Goiás, Goiânia, GO.
Telles, N. (2013). Escritoras, escritas, escrituras. In Priore, M. D. (Org.), História das mulheres no Brasil. (10. ed., pp. 669-672). São Paulo, SP: Contexto.

Touraine, A. (2007). O mundo das mulheres. Petrópolis, RJ: Vozes.

Tozetti, R., Cleto, M. C., Covolan, N. T., \& Signorelli, M. C. (2016). Gênero e Desenvolvimento Humano: a participação feminina na ciência. Revista Eletrônica Interdisciplinar, 9(1-2), 20-29.

UBER. (2020). Contribua para a segurança de todos. Recuperado de https://www.uber.com/pt-BR/

Vinuto, J. (2014). A amostragem em bola de neve na pesquisa qualitativa: um debate em aberto. Revista Temáticas, 22(44), 203-220.

Valente, E., Patrus, R., \& Guimarães, R. C. (2019). Sharing economy: becoming na Uber driver in a developing country. Revista de Gestão, 26(2), 143-160.

Wright, T. (2014). Gender, sexuality and male-dominated work: the intersection of long-hours working and domestic life. Work, Employment and Society, 28(6), 985-1002.

Yeung, N., \& Von Hippel, C. (2018). Stereotype threat increases the likelihood that female drivers in a simulator run over jaywalkers. Accident; analysis and prevention, 40(2), 667-674.

Zanatta, R. A. F. (2017). Economias do compartilhamento: superando um problema conceitual. In R. Zanatta, P. De Paula, \& B. Kira (Orgs.), Economias do Compartilhamento e o Direito (22a. ed., pp. 79-106). Curitiba, PR: Juruá.

Ana Paula de Oliveira Amaral Colodetti ORCID: https://orcid.org/0000-0001-7344-4006

Mestre em Administração pelo Centro Universitário Unihorizontes; Bacharel em Direito pela Faculdade de Direito da Universidade Federal de Minas Gerais (UFMG); Especialização em Ciências Penais pela Universidade Anhanguera-UNIDERP. E-mail: anapoamaral@gmail.com

Marlene Catarina de Oliveira Lopes Melo ORCID: https://orcid.org/0000-0002-9194-698X

Bolsista Sênior do CNPq; Professora Titular do Centro Universitário Unihorizontes; Professora Titular aposentada da Universidade Federal de Minas Gerais (UFMG); Diretora de Ensino, Pesquisa e Extensão do Instituto Novos Horizontes de Ensino Superior e Pesquisa Ltda., mantenedora do Centro Universitário Unihorizontes; Doutora em Ciências das Organizações pela Université Paris IX- Dauphine- França, 1983; Coordenadora do Núcleo de Relações de Trabalho e Tecnologia de Gestão - NURTEG. E-mail: marlene.catarina@unihorizontes.br 